\title{
Innovation Management in South Africa: An Inquiry
}

\author{
Derrick Herbst ${ }^{1} \&$ Brian Barnard ${ }^{2}$ \\ ${ }^{1}$ Henley Business School South Africa, University of Reading, Johannesburg, South Africa \\ ${ }^{2}$ Wits Business School, University of Johannesburg, Johannesburg, South Africa \\ Correspondence: Derrick Herbst, Henley Business School South Africa, University of Reading, Johannesburg, \\ South Africa. E-mail: d.herbst@webmail.co.za or barnard.b@polka.co.za
}

Received: June 14, 2016

Accepted: July 27, 2016 Online Published: August 29, 2016

doi:10.5539/jms.v6n3p34

URL: http://dx.doi.org/10.5539/jms.v6n3p34

\begin{abstract}
The study assesses innovation management in South African organizations, through semi-structured interviews. Some of the key attributes of innovation considered, include a) value proposition, b) organizational context, c) innovation process and management. Based on the interviews, some of the greatest challenges the organizations face are a) risk mitigation and management, b) innovation project evaluation and appraisal, as well as c) innovation process standardization and improvement. The conclusion is that innovation and innovation management still contain residual ambiguity. Still, there is always room at the top-organizations can still actively build their innovation competencies, from a range of dimensions, ranging from culture to process. No reason can be found why innovation can not be turned on itself-innovating innovation as organizational activity and competency.
\end{abstract}

Keywords: innovation, innovation management, innovation process, innovation appraisal

\section{Introduction}

\subsection{Drivers of Innovation}

Some of the reasons why companies may choose to innovate are a) increased competition, b) cost reduction, c) efficiency improvement, d) new technologies, e) customer expectations, f) stricter regulations, and g) corporate image. Correspondingly, some of the benefits of innovation are: a) improved productivity, b) better quality, c) extended product range, d) improved legal and environmental compliance, e) greater value added, f) improved staff motivation, retention and recruitment (Riley, 2015). Known risks of innovation include: a) competition, b) uncertain financial returns, c) limited financial resources (Riley, 2015).

Baker (2002, pp. 3-5) defines three types of innovation: product / service, process and strategy. Wong (2013, p. 712) extends this to four types of innovation, namely organizational, human capital, technical and marketing innovation. Christensen (1997, p. 10) classifies innovation as sustaining or disruptive, in contrast to the traditional view of incremental versus radical innovation.

\subsection{Defining Innovation}

Mikitani (2014) believes that it is important to differentiate between invention and innovation. Invention is the first occurrence of an idea for a new product or process. Now, according to Fagerberg, innovation is the first attempt to carry invention into practice (Fagerberg, 2003, p. 4). Greenstone \& Looney $(2011$, p. 2) claim that innovation is the process of discovering new ideas and realizing those ideas at large scale, changing the ways we live and work. George (2010, p. 1) recons that innovation occurs when someone uses an invention or an idea to change how the world works, how people organize themselves, or how they conduct their lives. George (2010, p. 2) even remarks that with the above-mentioned definition, innovation occurs whether or not the action of innovation succeeds in creating value for its titleholders. Furthermore, innovation is different from improvement in that it infiltrates society and can cause restructuring. With this definition, innovation occurs irrespective if the outcome was positive or negative.

Perhaps the definition provided by Greenstone \& Looney (2011, p. 2) can be greatly improved by merely substituting the word "changing" with "improving". The difference in the definitions may point out poor consensus on what innovation really is. The definition of innovation as defined in the statements above may lack evaluation criteria or a concise measure, and may thus complicate the articulation of innovation as concept and 
activity. The definitions make it clear that innovation requires practical realization or implementation. This then may point out its embedded complexity, constituting an extended and multi-faceted activity, and thus explain the divergence in definition.

\subsection{Innovation and Value}

It is postulated that innovation has purpose and intent. This is seen to be closely related to the concept of value - the purpose of innovation must be to realize a certain value proposition of some form, whether internal or external to the organization, or whether direct-readily measurable, as in the case of new products or services - or indirect - more difficult to quantify, as in the case of human capital innovation perhaps. Value is taken to entail value created and value captured. Value is created when the benefits outweigh or exceed the cost of the action taken. Verdin \& Tackx $(2015$, p. 2) define value creation as the perceived benefit to the customer. Value captured then is seen as the relative ability to realize value created-implement, or commercialize value created, and in doing so, benefit from value created. Both value creation and value capturing are seen as a necessary condition of innovation.

With value linked to innovation as desired outcome, innovation should thus have measurable criteria that can be used to guide and evaluate the innovation process over its entire span. This should include management, strategy, operations and marketing criteria.

\subsection{Innovation in the Organizational Context}

Both Wong (2013, pp. 712-714) and Verdin \& Tackx (2015, pp. 3-15) allude to the relationship between organizational culture, leadership, and innovation. From this, it is induced that organizations may have a culture conducive to innovation: innovation ideas and efforts are recognized, praised, and rewarded. Conversely, organizations may also have a culture non-conducive to innovation: the organization (management) is generally indifferent to innovation suggestions, do not value innovation attempts, and hardly reward such efforts. Leadership may actively pursue and drive innovation, in the sense that it is clear that leadership is a prominent and active driver, as well as a pursuer of innovation. The organization may pursue innovation for the right or wrong reasons: having realized its value, and thus being willing to invest in it, regardless of short-term ideals or objectives. Alternatively, leadership may see innovation as a quick solution to a deeper problem of solvency, or another objective. Also, the organization may or may not be geared towards learning, knowledge acquisition, revision, and adaption, generally seen as conducive to innovation.

\subsection{Innovation and Government}

The government is often revising regulation, especially in the manufacturing sector, in order to ensure sustainable development. Companies are often forced to operate more efficiently or to produce goods and products that are more efficient (Baker, 2002).

Governments can also drive innovation in organizations and companies with various funding models including grants and subsidies. The Support Programme for Industrial Innovation (SPII) is one such an example of government's efforts to fund innovation. This initiative of the South African Government in association with the Department of Trade and Industry (DTI) attempts to strengthen the country's competitiveness by prioritizing the development of new technologies (Support Program for Industrial Innovation, 2015).

At the same time, one should question whether such grants do not come with certain expectations from government that may be counter-productive or detrimental to innovation itself.

\subsection{Innovation as Process}

The innovation process comprises systematic steps, and can broadly be defined in three phases: conception, implementation, marketing (Tiwari, 2007). 


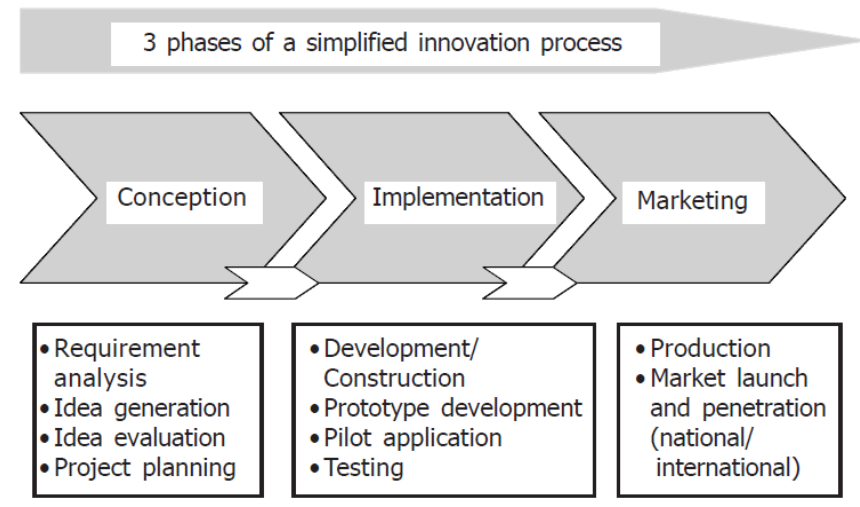

Figure 1. Simplified version of an innovation process (Tiwari, 2007)

Several theories have been developed over the second half of the last century in order to analyze and describe the nature of innovation. The coupling innovation process theory recognized that a push-pull theory represents reality better, and replaced the preceding technology push theory (Joseph Schumpeter) and the market pull theory (Jacob Schmookler). The Coupling theory suggests that innovation is sequential, but not necessarily continuous. The innovation process can be divided into a series of interdependent stages. The current stage might feed back to the previous stage. The different functions of the firm, as well as the technological and scientific community and marketplace, are linked together by a complex net (Godin \& Lane, 2013).

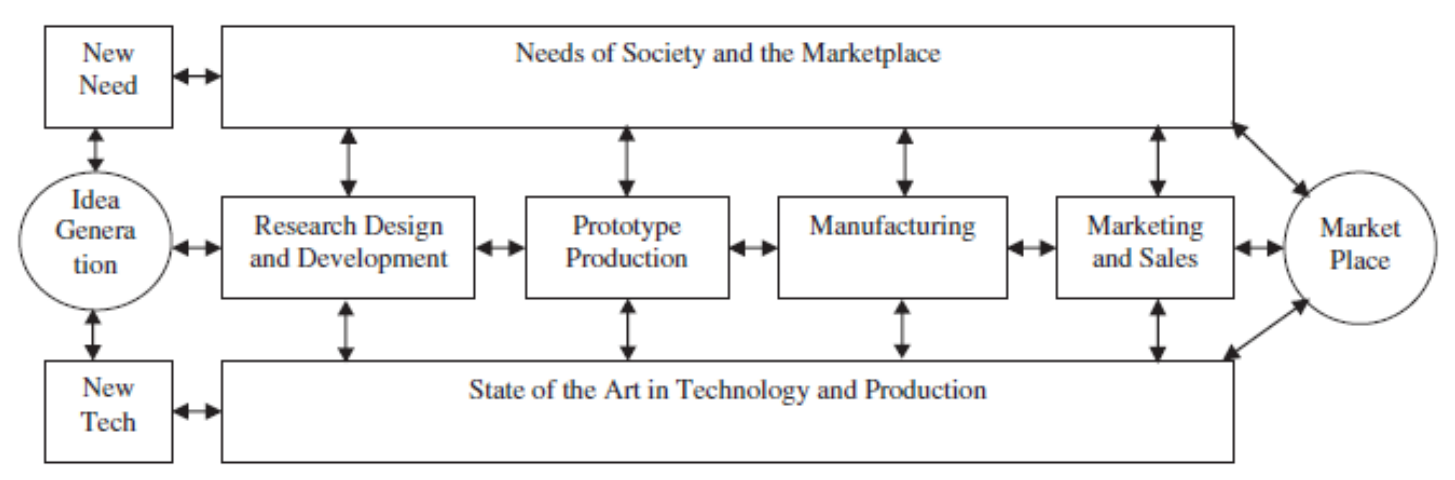

Figure 2. Coupling model (third generation) (Galanakis, 2006)

The Functional Integration Innovation Process Theory is recognized by its parallel instead of sequential mode. The core feature of this model is functional integration around a project in order to combine the expertise of the different specialists. This result is not only reduced completion time, but the rework needed at later stages of the process is also reduced (Galanakis, 2006).

The Systems Integration and Networking Innovation Process Theory features fully integrates parallel development with the use of expert systems and simulations modelling in research and development (R\&D). There is a strong linkage with leading-edge customers ("customer focus" at the forefront of strategy). Primary suppliers are strategically integrated and include co-development of new products as well as linked CAD systems. The horizontal linkages in this model include joint ventures, collaborative research groupings, and marketing arrangements etc. The emphasis is placed on corporate flexibility and speed of development (time-based strategy) with increased focus on quality and other non-price factors (Galanakis, 2006, p. 1224; Godin \& Lane, 2013, p. 636).

\subsection{Innovation roles and Activities}

Innovation can be seen as a sequence of information processing activities, and inputs from production, marketing, sales, finance, and R\&D functions are required. Jalonen $(2012$, p. 1$)$ defines innovation as a process that is fraught with uncertainty. Souder \& Moenaert (1992, p. 485) furthermore argue that innovation within a firm can be modelled as a process of reducing uncertainty. The four major sources of uncertainty, according to them, are 
user needs, technological environments, competitive environments, and organizational resources. Organizations generally reduce these uncertainties as part of the innovation process.

Different organizational functions as participants are uniquely positioned to optimally resolve the different uncertainties and drive necessary innovation effort. The three major participants are management, operations (research and development) and marketing (Souder \& Moenaert, 1992; Jalonen, 2012; Wong, 2013).

\subsection{Management}

Wong (2013, pp. 712-714) argues that senior management is key decision makers in an organization who are responsible for the setting of clear plans and policies, but also drive projects forward. They have the ability to create the right culture and organizational structure and are able to provide the necessary resources and motivational drive to deliver a project. Their positions should enable them to have direct access to critical information about the organization, as well as the market in which it operates. He further states that their positions should allow them to see and possibly utilize trends that are set and which ultimately affect the future of their organizations.

It is important to note that, no matter how innovation is represented, it remains a risky activity, and management's involvement plays a crucial role in mitigating the risks associated with innovation. Senior management's involvement with innovation includes acting as visionaries who help and support employees to explore innovative activities and drive necessary change. This involvement requires open and frequent communication on innovation decisions and projects. Extensive involvement leads to better information exchange, which in turn leads to earlier problem identification and resolution, and ultimately smoother management of innovation initiatives and projects. It is hypothesized that management involvement has a significant influence on innovation (Wong, 2013).

\subsection{Operations}

Souder \& Moenaert (1992) defines research and development (R\&D) roles as those which include the development of scientific and / or technical knowledge in order to achieve the organization's objectives. This includes research, development as well as technical services. Conception or idea generation may also involve resolving technical uncertainty about the operational and technical aspects of the innovation project- $\mathrm{R} \& \mathrm{D}$ effort - through additional investment (effort), given that firms may need to (first further) learn about and resolve opportunities and their potential profitability (Shepherd, 1999). In the event that management decides to continue with the development of a product, the R\&D function is responsible for transforming the product concept into a concrete and tangible product. This includes prototypes and pilot models to allow for testing as well as market feedback. As part of post-development, the final product might be further redesigned and redeveloped to further optimise it. Reasons for redevelopment could include product maintenance issues, marketing feedback of product use, or the implementation of product suggestions (Millson, 2012)

\subsection{Marketing}

The marketing department is expected to provide primary information concerning the definition of the problem from the customer's perspective, the user's needs, as well as information regarding the competition. This information is a key input to the planning stage of new product development (Souder \& Moenaert, 1992, p. 490; Song et al., 1996, pp. 546-547). While the new product is being developed by the operations department, the marketing department should continue with and further advance the development of detailed pricing, promoting, and distributing strategies. In addition, the marketing team should also start with the testing of prototypes and feed information back to the operations department (Millson, 2012). The post-development effort of the marketing department includes the market launch, new product marketing strategy implementation, tracking customer satisfaction, new product suggestions or changes, as well as product maintenance which may lead to product redesign (Millson, 2012).

\section{Method}

In order to form an assessment of innovation management- the depth and extent thereof - in South Africa, semi-structured interviews were conducted with executives, brand and marketing managers, strategy managers as well as entrepreneurs at various South African companies, ranging from SME to larger corporations. The interviewees have been directly involved in the innovation process at their organizations, with varying degrees of experience, but with not less than at least one year's experience, and, therefore, had developed the required experience and understanding of the topic that was researched. Fourteen interviews were conducted.

The interviewees were asked nineteen questions, divided into three sections. 
Table 1. Interview questions

Section 1-Introduction

Q1: How do you see innovation?

Q2: How innovative would you rate your company/ self?

Q3: What are your drivers of innovation?

Q4: What are some of the difficulties you struggle with regarding innovation?

Q5: What are some of the risks you experience as part of innovation, and how do you manage these?

Q6: How do you see the role of government in innovation?
This question served as an introduction to the interview. It was also used to test the subject's understanding of innovation.

This question also served as an introduction to the interview. Equally, it tested the subject's view of innovation.

This allowed interviewees to reflect on why their organizations innovate - the organizations' drivers of innovation.

The objective was to probe for the various difficulties and barriers associated with innovation.

The question seeks to understand how the organizations perceive, approach and manage uncertainty as part of innovation.

The question attempts to gauge organizations' perceptions regarding government involvement in innovation, and whether government was seen as helpful or hindering.

Section 2-Innovation, value and the organization

Q7: How important do you think is organizational culture in order to ensure successful innovation, and how do you see organizational culture contributing to innovation?

Q8: What do you deem as the purpose or intent of innovation?

Q9: What are some of the difficulties in building value into innovation projects?

Q10: How do you ensure that you capture value created during the innovation process?

Section 3-Managing the innovation process

Q11: Please describe the innovation process in your company-what are the steps involved?

Q12: What departments/ participants are involved in the innovation process? Please explain the roles/ involvement with each step.

Q13: What do you feel lacks in your innovation process?

Q14: How do you select your innovation projects?

Q15: What kind of input/ data do you focus on in managing projects?

Q16: How much time do you spend on your projects pre-prototype?

Q17: How do you measure the success of innovation projects, as the projects progress?

Q18: Have you ever decided to discard a project? If so, why?

Q19: How much is leadership involved in your innovation process? How do you view the role of leadership in innovation? Do you think leadership plays a vital role in terms of innovation?
The question reflects on perceptions regarding organizational culture organizational culture as part of innovation.

The question probed what organizations value in innovation, and attempt to achieve through their innovation projects.

This question aims to understand how companies ensure they build sufficient value into their innovation attempts.

This question was included to determine how companies ensure that they capture value created through innovation.

This question is asked to understand what, if any, innovation process is employed in the organizations.

Arguably, the entire company should be involved in the innovation process. Each department has its own role in the process. The objective is to determine what departments are involved, and what role they are playing.

This question determines if there are any perceived shortcomings in the innovation process.

This question prompts project selection methods.

Innovation is also a risk reduction process. As a result, various sets of data should be obtained and checked throughout the process.

This question aims to understand how much time of the overall innovation project is spent on planning.

Innovation could be seen as a project, and should therefore be managed as such. As with any project, several milestones and checkpoints should be defined as part of the process.

This question was included to determine if companies readily evaluate projects, and abandon unfeasible projects.

This question probed perceptions regarding, and actual behavior of, management in terms of innovation. in the context of innovation, as well as the management of

\section{Analysis}

Below, the transcribed interviews:

Q1: How do you see innovation? All the subjects responded with very similar answers. The general theme was that innovation is the ability to generate new or different ideas and concepts. Furthermore, the general feeling was that it does not have to be something entirely new, as an adjustment or improvement could also be made to something that already exists. They also felt that innovation should, at least, result in an improvement, reduce resources required, or make a product or service more accessible. Furthermore, one subject argued that innovation is necessary, especially in difficult economic times. Another subject stated that innovation is the ability to solve a very specific need, without copying it from somewhere else.

Q2: How innovative would you rate your company/ self? Almost all of the subjects rated their company's 
innovation capability above average, with an average score of 7 out of 10 . Various reasons were given for this high score. One of the subjects attributed this to their ability to take an idea and expand it into a product, without merely copying it. Another subject rated its company as innovative, due to the fact that they manage to release between five and six game-changing innovations in a single year. However, two of the subjects did not share the same sentiment about their companies and felt there is room for improvement with regards to innovation. One subject stated that its company did in fact recently invest money in innovation; nonetheless, the interviewee did not agree with the manner in which the money was spent and felt that there were better ways to invest it in innovation. One of the subjects rated its company's innovation capability at 4 out of 10 - the subject was of the opinion that the company is attempting various innovations, but is failing at most of them. Furthermore, some felt their companies do not get the final implementation right.

Q3: What are your drivers of innovation? Various drivers of innovation were identified. Cost reduction seems to be the biggest reason to pursue innovation projects, with five of the subjects stating this as a primary driver of innovation. This is closely followed by market demand, which earned four votes as a primary innovation driver. Equally important are obtaining a competitive edge and business sustainability, and were marked as important by four of the subjects, respectively. Two of the subjects stated that they had started with innovation projects within their own organizations, as they got frustrated with the general lack of innovation whilst being employed by bigger companies. The thrill of new things was also listed by one of the subjects as a driver for innovation.

Q4: What are some of the difficulties you struggle with when it comes to innovation? Even with all the reasons to innovate, the companies experienced challenges that hamper their innovation. Lack of resources topped the list of challenges that companies are confronted with, when they attempt to innovate. Money was cited by eight of the subjects as a limiting factor. Limited knowledge and human resources within the company were cited by three of the subjects as a difficulty. Furthermore, three of the subjects stated that limited time was a barrier to innovation. Another barrier identified by two of the subjects was a company culture that is not conducive to innovation. This goes hand in hand with bureaucracy and red tape, which were a concern for two of the subjects. Finally, lack of implementation was highlighted by one of the subjects as an innovation obstacle.

Q5: What are some of the risks you experience in innovation, and how do you manage these? Four of the subjects stated that their biggest concern in terms of innovation is market acceptance - if the market did not want or need the innovation and, therefore, did not accept it, then the innovation would be considered a waste. It is then understandable that five of these respondents worry about the risk of not being able to fully recuperate the development costs of the innovation project. Furthermore, four of the subjects named the time to market of a new product as one of the risks when dealing with innovation projects. Another concern highlighted was the risk that the company would not be able to complete the project, as stated by one of the subjects. Intellectual property protection was highlighted by another subject as a risk to consider.

Q6: How do you see the role of government in innovation? The question regarding the role that government plays in innovation was a sensitive topic during the interviews, and most subjects reacted rather negatively to it. One subject even went as far as stating that his company has never, and will never, do business with the government. Six of the subjects felt that there are too much red tape and conditions, when approaching the government for innovation funding. Four did not even know about any innovation grants made available by the government. About one-fifth of the subjects felt that the government is non-existent in terms of innovation. Two of the subjects argued that the government should provide an innovation framework through research houses, incentivize companies to innovate, and manage the entire innovation grant process better, including making funding available more readily and more quickly.

Q7: How important do you think is organizational culture in order to ensure successful innovation, and you do you see organizational culture contributing to innovation? The majority of the subjects agreed that organizational culture plays a vital role in innovation. Almost three-quarters of the subjects agreed that it is crucial while six subjects argued that organizational culture could make or stifle innovation. Only one of the subjects argued that organizational culture is not important for successful innovation.

Q8: What do you deem as the purpose or intent of innovation? The replies had a general theme of improvement. Five of the subjects argued that their companies innovate in order to improve their products, services, or systems. The same amount of subjects also argued that innovation leads to a competitive advantage. Four of the subjects stated there is a direct link between company growth (or stagnation) and innovation. Furthermore, according to three of the subjects innovation could also lead to a reduction in resource consumption. However, only two of the subjects made a direct link between innovation and profitability. One of the subjects stated that innovation makes new technology more accessible, whilst another subject argued that a more 
innovative brand is perceived as a more premium brand by its customers.

Q9: What are some of the difficulties in building value into innovation projects? It was evident that the subjects were not very familiar with the concepts of value creation and value capturing. The interviewer had to clarify the question in various interviews. Seven of the subjects argued that the final value of the innovation is decided by the market. This makes the innovation process very risky, and most of the subjects do market research before, during, and after the innovation process in order to ensure an alignment between the market expectations and company outputs. One of the subjects stated that the innovation project must be original, as well as cost effective. Another subject argued that the entire cost of the innovation might not necessarily be recuperated; however, the innovation is still important as it will not only draw new customers, but also retain customers.

Q10: How do you ensure that you capture value created during the innovation process? The majority (five) of the subjects looked at market feedback and customer satisfaction to determine value capturing. Three of the subjects stated that intellectual property protection is important in order to maximize the value captured through innovation projects. The same number of subjects relied on marketing to build their brand in an effort to capture as much value as possible. Two of the subjects relied on passive income generating schemes to maximize value captured. Shortening the time to market, brand building innovations, and added valued services each received a vote from individual subjects as methods to increase value captured.

Q11: Please describe the innovation process in your company—what are the steps involved? Although most of the companies follow a linear innovation process, the actual process varies significantly between the various companies. Two of the subjects were sub-contracting the innovation process. One of the subjects stated that they do not have any formal innovation process, as it will hamper innovation. According to three of the subjects, their process is simple and consists of idea generation, development, and marketing. Seven of the subjects included some preliminary planning in their innovation process before starting with the development. Only three of the subjects included an innovation selection phase in their innovation process, and the same percentage of the subjects had a testing phase before commercializing the innovation.

Q12: What departments/ participants are involved in the innovation process? Please explain the roles/ involvement with each step. Six of the interviewees stated that the entire organization is involved in the innovation process. All the individual departments have a specific function in the innovation process, in order to ensure the overall success of the initiative. In contrast with this, several subjects highlighted only individual departments that are actively involved in the innovation process. Also, one subject argued that only the business owner is involved in innovation, and has to fulfill the role of the entrepreneur as well as the designer. Another subject argued that innovation is mainly the role of the manufacturing department. Three subjects argued that the combination of customer interaction and research and development departments are the main role players regarding innovation in their companies.

Q13: What do you feel lacks in your innovation process? A lack of resources was stated by nine of the subjects as the biggest deficiency of the innovation process. Six subjects argued that their innovation process could be greatly enhanced if they had access to additional time and financial resources. Two subjects identified a shortage of knowledge and skills within the organization as a limitation. One subject stated that they do not have access to the advanced technology required for their innovation initiatives. Two of the subjects felt that the innovation process is fractured and that interdepartmental communication is hampering the process, while another subject argued that the entire company should be involved in the innovation process. Other limitations were also mentioned, including lack of documentation, evaluation, and market feedback, which was cited respectively by individual subjects. Interestingly, one of the subjects argued that they do not lack anything in their innovation process.

Q14: How do you select your innovation projects? Ten of the subjects stated that their innovation projects are selected based on customer demand, while four of the subjects' companies use increased productivity or cost saving drivers. Three of the subjects would select innovation projects based on the available time and resources within the company, while another three subjects use personal flair or "gut-feeling" to select the projects. Only one of the subjects stated that innovation decisions are made at senior executive level.

Q15: What kind of input/ data do you focus on in managing projects? It seemed as if some of the subjects did not quite understand this question, as many of them referred to project selection methodology rather than the actual project management itself. The majority of the subjects (ten) stated that they refer to customer requirements and market research when managing innovation projects. Three of the subjects referred to traditional project management theory to manage the project, by breaking it down into segments, assigning 
milestones and managing the critical path carefully. Only one of the subjects considered input cost as part of the innovation management process.

Q16: How much time do you spend on your projects pre-prototype? The individual companies all spent different lenghts of time on their innovation projects, and the answers given varied widely. Two of the subjects argued they are planning too much, which is risking the actual implementation of the innovation. In contrast to this, one subject stated that they are not planning enough. Two of the subjects stated that the planning phase varies depending on the type and size of the innovation. One of the subjects stated that planning should take up a minimum of $40 \%$ of the overall project's time while two of the subjects specified that between $20-30 \%$ of the overall project's time is sufficient to plan for the project. Five subjects identified that planning can take anything from one to eight months, while one of the subjects stated that planning takes at least one year.

Q17: How do you measure the success of innovation projects, as the projects progress? Seven of the subjects refer to customer satisfaction and market feedback to determine the success of the innovation project. Four of the subjects look at volume and profit margins to measure the success, while the same number of subjects analyze the cost reduction, management, and success factors. Three of the subjects utilize project milestones to determine whether the project is successful. Two subjects quantify various bases and use these as a checklist to determine overall project success. In addition to this, one of the subjects refer to industry specifications as a measure of the project's success.

Q18: Have you ever decided to discard a project? If so, why? Only three of the subjects said they never had to cancel an innovation project. The remainder of the subjects all have discarded innovation projects during the course of the project. Four subjects stated a lack of resources, whether it is limited technology or finance available, as the reason for discarding innovation projects. Feasibility, a similar product already existing in the market, or the market rejecting an innovation project, were respectively voted by two of the subjects as the reason why they had to cancel a project. One of the subjects had to stop a project due to the technical functionality that was not up to standard.

Q19: How much is leadership involved in your innovation process? How do you view the role of leadership in innovation? Do you think leadership plays a vital role in terms of innovation? All of the subjects agreed that leadership is critical in innovation. Nine of the subjects stated that leadership drives, guides, and steers innovation in the company. Without leadership, the innovation would not reach its intent, while three of the subjects stated that leadership makes the final decision regarding innovation projects. A few subjects argued that, even if the consumers request a new product or service, if the higher powers do not see it as a feasible proposition, it would not be developed. Furthermore, the innovation culture of a company is determined by its leadership, according to four of the subjects. Also, it is the responsibility of leadership to facilitate resources (two subjects), motivate, and manage change (one subject), and to set the example (one subject).

\section{Conclusion}

From the study, it is clear that the subjects from various backgrounds and companies comprehend the general theme of innovation. The classic drivers to pursue innovation persist throughout the companies. Nonetheless, it seems that innovation as concept is still rather individually or subjectively considered, to some extent. This may hinder communication and articulation with regards to innovation. The majority of the interviewees stated that their biggest hindrance regarding innovation is limited resources. These resources were typically accepted to be expensive, without any effort to probe the actual cost, or to improve innovation processes - that is, innovating innovation as process itself. The lack of process further haunts these companies with increased innovation risk, including market acceptance, development cost recovery and time to market. Improving innovation may require a greater acceptance, acknowledgement and delineation—standardization —of innovation processes.

A further concern is the methods used to select and appraise innovation projects. The interviewees were not quite aware of the concept of value creation and value capturing, therefore arguably complicating the appraisal, measurement, and evaluation of their innovation projects. Even after a project was started, the methods used to monitor the progress seem lacking. Overall, innovation project evaluation and appraisal seem to be periodical at best, rather than more continuous over the lifetime or cycles of the project—generally delayed or postponed to occur at the end of the project only. Innovation project evaluation also seems to build on broad and subjective measures. Most of the subjects included some form of planning in innovation projects, but the majority of them do not seem to overly perceive benefit in planning. Arguably, this may result in projects being discarded at a later stage. It is questioned whether the organizations can not improve innovation outcomes by an increased focus on concept design, marketing, and management. Related to this, risk management as part of innovation also seems lacking in certain cases. 
The majority of the subjects stated that culture is vital to innovation and the organization, yet it is questioned whether these companies actively cultivate innovation cultures. In some cases, only certain parts of the company focused on innovation, and holistic innovation teams are arguably absent. All of the subjects agreed that leadership plays an important role in an innovative organization. Nonetheless, it appears that some of the individual leaders lack certain skills to successfully manage innovation projects, suggesting the need for further training and coaching.

With regards to government's role and involvement, the general feedback from the study was generally negative, as most of the subjects criticized the government's attempt at improving innovation in the country, for various reasons.

Table 2 summarizes some of the varying perspectives and actualities regarding principal innovation concepts, surfaced by the study.

Table 2. Contrasting perspectives and actualities regarding principal innovation concepts

\begin{tabular}{|c|c|c|}
\hline Concept & Practice & Ideal \\
\hline \multirow[t]{2}{*}{ Innovation as concept } & Difficult to understand, articulate & Analyzed; studied \\
\hline & Subjectively understood & Objectively consolidated \\
\hline Value & $\begin{array}{l}\text { Value is seen as a posteriori-value is } \\
\text { essentially discovered }\end{array}$ & $\begin{array}{l}\text { Value is seen as a priori possible_-value } \\
\text { can be discovered and conceptually } \\
\text { understood }\end{array}$ \\
\hline Organization & Decentralized; scattered & Consolidated \\
\hline Sources of opportunity & Predominantly empirical— data driven & Empirical and conceptual \\
\hline Recognizers of opportunity & Market; operations; marketing; management & $\begin{array}{l}\text { Market; operations; marketing; } \\
\text { management; concept designers }\end{array}$ \\
\hline Selection of projects & Subjective/ expert orientation & Cognitive; structured; holistic; collective \\
\hline Management & Passive; detached; periodical & $\begin{array}{l}\text { Centralized; central; active; frequent; } \\
\text { facilitating; informed }\end{array}$ \\
\hline \multirow[t]{2}{*}{ Process } & $\begin{array}{l}\text { Viewed as non-existent; complex; } \\
\text { impossible; random }\end{array}$ & $\begin{array}{l}\text { Viewed as possible; improvable; } \\
\text { standardize-able }\end{array}$ \\
\hline & $\begin{array}{l}\text { Subjective process followed (what works for } \\
\text { you) }\end{array}$ & $\begin{array}{l}\text { Routines; procedures; processes created; } \\
\text { evaluated; and improved }\end{array}$ \\
\hline Input & Localized with experts & Publicized; consolidated \\
\hline \multirow[t]{2}{*}{ Participant appraisal and reward } & Project-based; experts-based & Knowledge-based; effort-based \\
\hline & $\begin{array}{l}\text { Experience-oriented-experience is } \\
\text { rewarded }\end{array}$ & $\begin{array}{l}\text { Learning-oriented-ability to learn and } \\
\text { comprehend is equally rewarded }\end{array}$ \\
\hline Project management and appraisal & $\begin{array}{l}\text { Erratic; subjective-done at will when } \\
\text { viewed as important against subjective } \\
\text { measures }\end{array}$ & $\begin{array}{l}\text { Continued; management-centralized; } \\
\text { objective constraints used and data driven }\end{array}$ \\
\hline Culture & $\begin{array}{l}\text { Erratic-innovation: the outcome of } \\
\text { innovation is more strongly valued than } \\
\text { innovation as activity }\end{array}$ & $\begin{array}{l}\text { Consistent; sustained innovation: benefit of } \\
\text { innovation recognized and valued }\end{array}$ \\
\hline
\end{tabular}

\section{References}

Baker, A. K. (2002). Innovation. Retrieved from http://www.au.af.mil/au/awc/awcgate/doe/benchmark/ch14.pdf

Christensen, C. M. (1997). The Innovator's Dilemma. Boston: Harvard Business School.

Fagerberg, J. (2003). Innovation: A Guide to the Literature. Centre for Technology, Innovation and Culture, University of Oslo.

Galanakis, K. (2006). Innovation process. Make sense using systems thinking. Coventry: Elsevier.

George, S. K. (2010). Innovation vs. Invention. Retrieved from www.schoolnet.org.za/conference/sessions/SKG/InnovationHandoutPacket.pdf

Godin, B., \& Lane, J. P. (2013). "Pushes and Pulls": A History of the Demand Pull Model of Innovation. Quebec.

Greenstone, M., \& Looney, A. (2011). A Dozen Economic Facts about Innovation. Washington, DC: The Hamilton Project. 
Jalonen, H. (2012). The Uncertainty of Innovation: A Systematic Review of the Literature. Journal of Management Research, 4(1), 1-47.

Mikitani, H. (2014). Innovation vs. Invention. What's the Difference? Retrieved from https://www.linkedin.com/pulse/20140107141518-52782505-innovation-vs-invention-what-s-the-difference

Millson, M. R. (2012). An Empirical Exploration of the New Product Process Proficiency-New Product Success Relationship. International Journal of Business and Information, 7(1), 1-29.

Riley, J. (2015). Innovation-Benefits and Risks. Retrieved from http://beta.tutor2u.net/business/reference/innovation-benefits-risks

Shepherd, D. A. (1999). Venture Capitalists' Assessment of New Venture Survival. Management Science, 45(5), 621-632. http://dx.doi.org/10.1287/mnsc.45.5.621

Song, X. M., Neeley, S. M., \& Zhao, Y. (1996). Managing R\&D Marketing-Marketing Integration in the New Product Development Process. Industrial Marketing Management, 25(6), 545-553. http://dx.doi.org/10.1016/S0019-8501(96)00069-7

Souder, W. E., \& Moenaert, R. K. (1992). Integrating marketing and R\&D project personnel within innovation projects: An information uncertainty model. Journal of Management Studies, 29(4), 485-512. http://dx.doi.org/10.1111/j.1467-6486.1992.tb00675.x

Support Program for Industrial Innovation. (2015). Support Program for Industrial Innovation. Retrieved from www.spii.co.za

Tiwari, R. (2007). The early phases of innovation. Hamburg: Hamburg University of Technology.

Verdin, P., \& Tackx, K. (2015). Are You Creating or Capturing Value? A dynamic framework for sustainable strategy. Harvard Kennedy School.

Wong, S. K. S. (2013). The role of management involvement in innovation. Management Decision, 51(4), 709-729. http://dx.doi.org/10.1108/00251741311326527

\section{Copyrights}

Copyright for this article is retained by the author(s), with first publication rights granted to the journal.

This is an open-access article distributed under the terms and conditions of the Creative Commons Attribution license (http://creativecommons.org/licenses/by/4.0/). 